\title{
SOME ASPEGTS OF TERPENOID AND STEROID CHEMISTRY
}

\author{
D. H. R. BARToN \\ Chemistry Department, Imperial College of Science and Technology, \\ London, U.K.
}

The lactonic bitter principles comprise an important group of natural substances. If we exclude from consideration the coumarins, compounds which do not present great difficulties in structural elucidation, then there remains a large family of bitter principles whose biogenesis appears to be of the terpenoid (mevalonic acid) type. Compounds of this latter kind have presented challenging problems for generations, but it is only in the last decade that their constitutions have received serious attention. Because of the limited time available for this lecture, only work from our own group can be discussed. This does not, of course, mean that others have not also been making important contributions to the field.

We may commence by listing some of the interesting constitutions that our group has studied during the last few years. First comes tenulin (I) ${ }^{1}$, chiefly remarkable for the ease with which it rearranges under very mildly alkaline conditions (boiling London tap water!) into isotenulin (II), which has a true acetate grouping. Secondly, we may mention lactucin (III) ${ }^{2}$, a compound of alleged medicinal value, which has an interesting cross-conjugated dienone system. Thirdly, comes geigerin (IV) ${ }^{3}$, a compound to which we shall make further reference later. Fourthly, let us consider pyrethrosin $(\mathrm{V})^{4}$, of especial interest as it was the first sesquiterpenoid in which a ten-membered ring was shown to be present. This feature was recognized as being of biogenetic significance, a view which has been abundantly confirmed by later work ${ }^{5}$. These compounds contain sesquiterpenoid skeletons based directly upon a cyclized farnesol chain without rearrangement of the carbon skeleton ${ }^{6}$. The diterpenoid derivative, columbin (VI), the main bitter principle of Colombo root, is different in that the two methyl groups have, according to biogenetic hypothesis, been moved from their original positions in a skeleton as in (VII) ${ }^{7}$.

These examples will serve to show the wide variety of functional groups that one finds in the lactonic bitter principles. The problems of structural elucidation are, in fact, as difficult as one wishes to make them. Perhaps we can illustrate this, as well as the interesting types of reaction that can be discovered incidentally to the investigations, by considering our recent work on the citrus bitter principles. Limonin is the characteristic bitter principle of citrus species occurring in all parts of the plant. The literature on this compound has been detailed in a recent paper ${ }^{8}$, and we shall cite here only those references especially pertinent to our own work.

Our investigations on the constitution of limonin were initiated in Glasgow in 1956, and have been continued to the present time. From the outset, we 


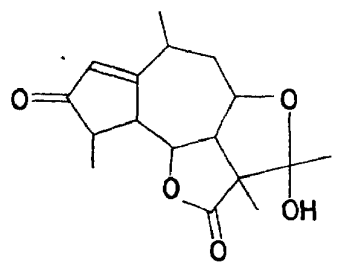

(1)

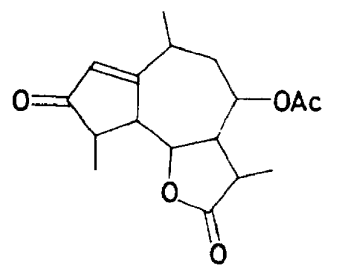

(II)

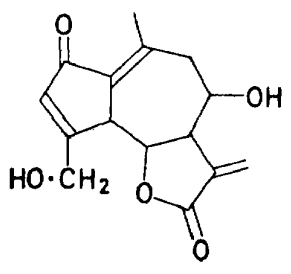

(III)

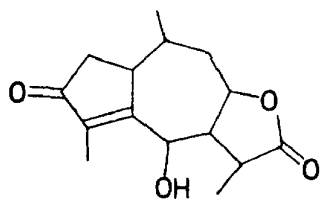

(IV)

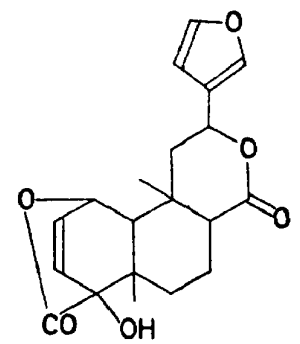

(VI)<smiles>C=C1C(=O)OC(CC2(O)CCCC(C)=CC2OC(C)=O)C1C(C)=O</smiles>

(V)<smiles>CCC(C)CCC1C(C)CCC2C1CCCC2(C)C</smiles>

(VII)

collaborated with Professor Robertson in an X-ray investigation which eventually (see below) made an important contribution to the problem.

Chemical work on the constitution of limonin has also been in progress in Zürich in the laboratories of Professor Jeger and Dr Arigoni, and at Urbana, Illinois, under the direction of Professor Corey. During the last three years, there has been an exchange of information and free discussion of the problem, and the conclusions reached on the chemical side (summarized in a recent joint communication ${ }^{9}$ ) represent a collaborative effort. We shall make reference to the X-ray work at Glasgow ${ }^{4}$ and to other chemical investigations where this is relevant to our presentation.

The constitution and stereochemistry of limonin, $\mathrm{C}_{26} \mathrm{H}_{30} \mathrm{O}_{8}$, can be represented $^{9-11}$ as in (VIII). From the biogenetic point of view, the compound is a tetracyclic triterpenoid of the euphol (IX) type ${ }^{12}$ from which four carbon atoms at the end of the side chain have been removed and carbon atoms $\mathrm{C}-20$ to $\mathrm{C}-23$ then converted into a furan ring. Ring A of the triterpenoid skeleton has been oxidatively cleaved between $\mathrm{C}-3$ and $\mathrm{C}-4$, and the C-3-carboxyl thus formed oxidatively cyclized on to C-19. The constitution of limonin also requires an oxidative cleavage of the Baeyer-Villiger type upon a 16-ketone in the skeleton of (IX) to give the 


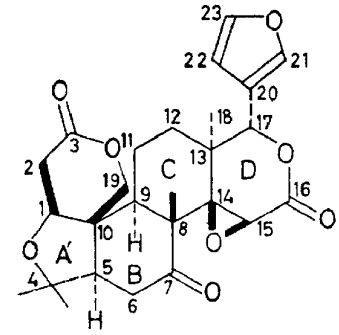

( VIII)

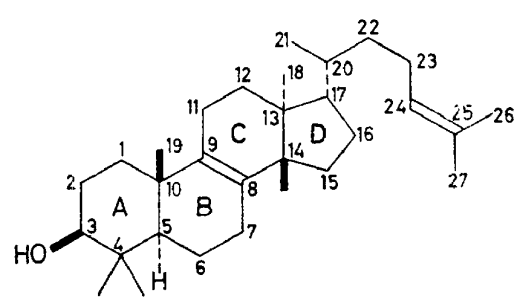

(IX)

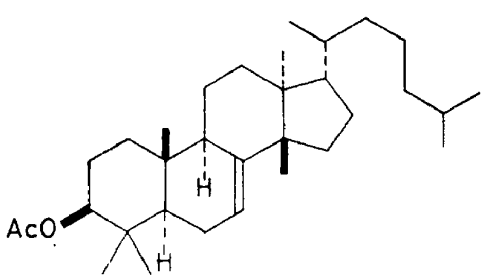

$(x)$

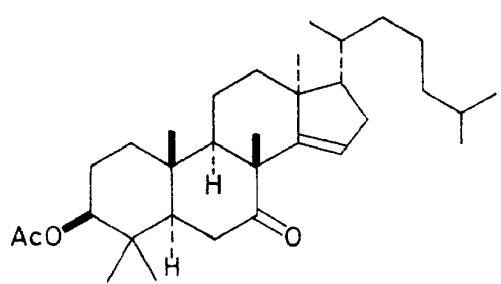

$(\mathrm{XI})$

ring D lactone. Finally, one methyl group must be migrated from C-14 to G-8. It is of interest that chromic acid oxidation of dihydrobutyrospermol acetate (X) furnishes the compound (XI) ${ }^{13}$ which has a 7-ketone group, an ethylenic linkage between $\mathrm{C}-14$ and $\mathrm{C}-15$ and a $\beta$-methyl group moved from C-14 to C-8. It is attractive to suppose that an equivalent mechanism operates in the plant in the biogenesis of limonin. The numbering and lettering systems in limonin (VIII) follow directly from these biogenetic considerations, and are the same as in other tetracyclic triterpenoids ${ }^{14}$.

The absolute configuration of limonin, expected from the biogenetic arguments developed above, has been confirmed by the rotatory dispersion curve $^{15}$ method $^{9}$, the measurements being kindly made by Professor Klyne of the Postgraduate Medical School, London.

Work published either before, or during, our own investigations had shown ${ }^{8,9}$ that limonin contains two $\delta$-lactone rings, which can be opened reversibly with alkali, a $\beta$-substituted furan residue, a ketonic oxygen present in a six-membered (or larger) ring, and two ethereal oxygen cycles. Hydrogenation of limonin gives tetrahydrolimonin, $\mathrm{C}_{26} \mathrm{H}_{34} \mathrm{O}_{8}$, and hexahydrolimoninic acid, $\mathrm{C}_{26} \mathrm{H}_{36} \mathrm{O}_{8}$. The furan ring is saturated in both compounds, and the acid is formed by hydrogenolysis of one of the lactone rings. There is good evidence ${ }^{8,9}$ that this lactone cleavage is caused by having the alkyl oxygen of the lactone in the allylic relationship to the furan ring. An exactly comparable situation is found in columbin? Hexahydrolimoninic acid is abnormally strong ${ }^{16}$, a fact which is conveniently explained by attaching one of the ethereal oxygen atoms in the $\alpha$-position. The part formula (XII) is thus established ${ }^{8}$. 


\section{H. R. BARTON}

The ketone group of limonin can be reduced stereospecifically by the Ponndorff-Meerwein procedure ${ }^{17}$ to give the axial alcohol limonol ( (XIII): $\left.\mathrm{R}=\mathrm{OH} ; \mathrm{R}^{\prime}=\mathrm{H}\right)$. On the other hand, reduction with borohydride or with sodium amalgam gives the equatorial epilimonol ( (XIII): $\mathrm{R}=\mathrm{H}$; $\left.\mathrm{R}^{\prime}=\mathrm{OH}\right)$. We have converted epilimonol into its chloroacetate and thence into the iodoacetate ( $\left.(\mathrm{XIII}): \mathrm{R}=\mathrm{H} ; \mathrm{R}^{\prime}=\mathrm{O} \cdot \mathrm{CO} \cdot \mathrm{CH}_{2} \mathrm{I}\right)$. It is the latter compound which was used in the $\mathrm{X}$-ray work of Robertson and his colleagues ${ }^{10}$.

Treatment of limonin with hydriodic acid gives first deoxylimonin, $\mathrm{C}_{26} \mathrm{H}_{30} \mathrm{O}_{7}$ (XIV) ${ }^{18}$, and then citrolin, $\mathrm{C}_{26} \mathrm{H}_{28} \mathrm{O}_{6}{ }^{16,18}$. Further reference to these compounds is made below.

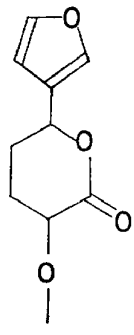

(XII)

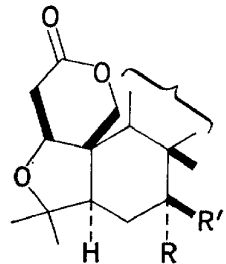

(XIII)

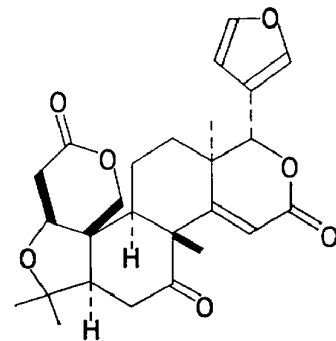

(XIV)

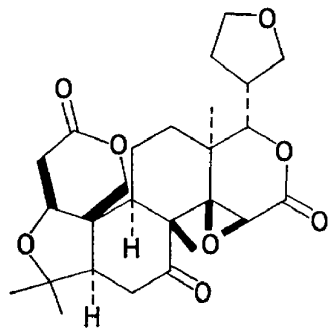

(XV)

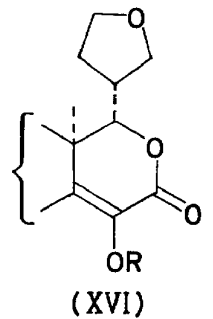

(XVI)

The molecular formula of limonin, when coupled with knowledge of the functional groups, requires that the molecule be bicarbocylic. Since drastic degradation ${ }^{19}$ of limonin yields 1,2,5-trimethylnaphthalene, one can assume tentatively that the two carbocycles are both six-membered.

We now develop our own arguments in support of the constitution (VIII). The formation of the $\alpha, \beta$-unsaturated lactone deoxylimonin from the action of hydriodic acid on limonin suggests the presence of a 1,2-epoxide ${ }^{20}$. Conjugation of this epoxide with the ring $\mathrm{D}$ lactone is shown by the fact that treatment of tetrahydrolimonin (XV) with hydrochloric-acetic acid mixture under controlled conditions gave iso-tetrahydrolimonin, an enolized $\alpha$-keto-lactone $((\mathrm{XVI}): \mathrm{R}=\mathrm{H})$, characterized as its acetate ( $(\mathrm{XVI})$ : $\mathrm{R}=\mathrm{Ac})$. The presence of the enolic system, established by a ferric reaction 
and by spectroscopic data, was confirmed by ozonolysis followed by mild hydrolysis, a procedure which yielded oxalic acid.

Treatment of tetrahydrolimonin with hydriodic acid under controlled conditions gave deoxytetrahydrolimonin (as (XIV)), also prepared by selective hydrogenation of deoxylimonin (XIV). Deoxytetrahydrolimonin was, as expected, stable to acid under the conditions specified above. This and other experiments indicated that the second ethereal oxygen was probably not present as a 1,2- or 1,3-epoxide.

The action of hydrochloric acid-acetic acid on hexahydrolimoninic acid (XVII) gave a neutral isomer containing (from the infra-red absorption spectrum) a $\gamma$-lactone ring. This is formulated as (XVIII) and, in agreement, oxidation with pyridine-chromium trioxide afforded an $\alpha$-keto-

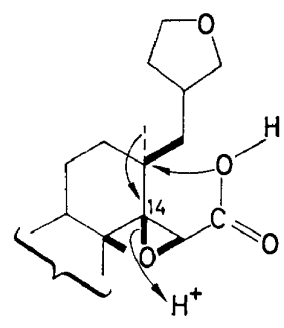

(XVII)

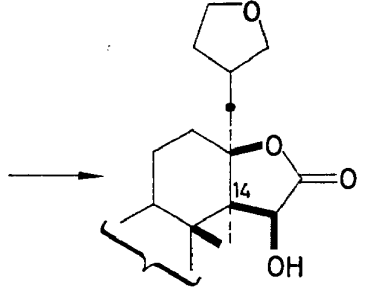

(XVIII)

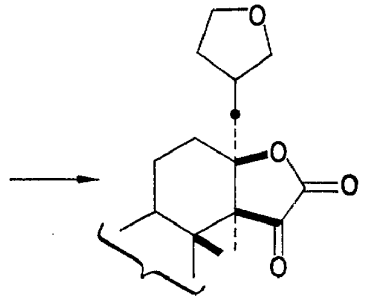

$(X I X)$

lactone (XIX) which could not be made to enolize. One must conclude from this that the original isomerization of (XVII) has placed a new carboncarbon bond at $\mathrm{C}-14$ in accordance with the formula (XVIII). Our own work does not prove that the migrating group is methyl. This is, however, shown conclusively by work carried out at Zürich and Urbana ${ }^{9}$.

The relationship between the ketone group of limonin and the lactone ring $\mathrm{D}$ was disclosed by the following experiments (and also other work ${ }^{9}$ ). Treatment of deoxylimonin (XIV) under lactone titration conditions gave a non-conjugated carboxylic acid, $\mathrm{C}_{26} \mathrm{H}_{32} \mathrm{O}_{8}$, which still retained the two lactone residues but no longer responded to spectroscopic or chemical tests for the ketone group. Deoxylimonin oxime is stable under the same conditions of alkalinity so that it must be attack by hydroxyl ion upon the ketone group which initiates the reaction. All these facts are consistent with a reaction course indicated by the arrows in $(\mathrm{XX})$ to give $(\mathrm{XXI})$ as the structure of the acid, now conveniently designated as deoxylimonic acid. Similarly, deoxytetrahydrolimonin (as (XIV)) gave deoxytetrahydrolimonic acid (as (XXI)).

The further reactions of deoxytetrahydrolimonic acid have confirmed the structure assigned. It reacted with one mole of chlorine to give an adduct ((XXII) or equivalent) which was too unstable to be isolated. Heating in vacuo afforded a mixture of two crystalline diene-acids, both characterized as their methyl esters. The major product had a broad absorption band at $255 \mathrm{~m} \mu$ and a low $\epsilon$ value (7800) in agreement with a cisoid-diene-structure (XXIII). It gave formaldehyde on ozonolysis and had three vinyl-type

$$
\text { P.A.C. } 2-(3-4)-\mathrm{I} 4
$$


D. H. R. BARTON

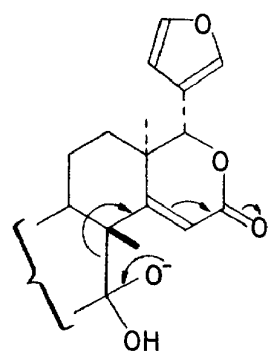

$(\mathrm{XX})$<smiles>C=C1C2=CC(=O)OC(C3CCOC3)C2(C)CCC1CCCCC(=O)O</smiles>

(XXIII)

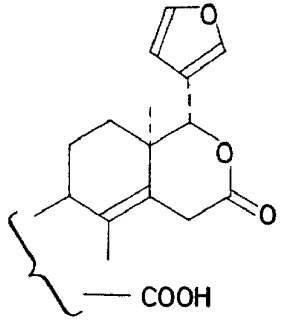

$(\mathrm{XXI})$<smiles>CC(=O)OCCCC1CCC2(C)C(=CC(=O)OC2C2CCOC2)C12CO2</smiles>

(XXIV)

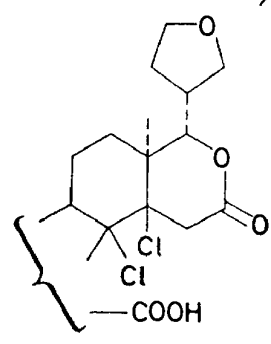

(XXII)

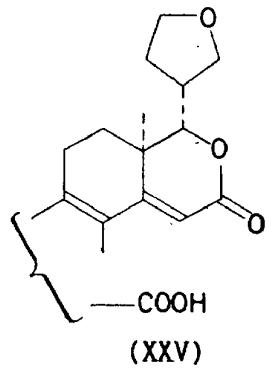

protons in its nuclear magnetic resonance spectrum, two $(\tau=4.60$ and 4.38 ) indicative of an exocyclic methylene group, or equivalent structure, and one $(\tau=3.97)$ consistent with the presence of a vinyl hydrogen $\alpha$ - to a lactone grouping (as in ring D). The acid (XXIII) was further characterized as the epoxide (XXIV) which showed a normal $\alpha, \beta$-unsaturated lactone spectrum comparable to that of deoxylimonin. The minor product from heating (XXII) was a transoid-diene-lactone (XXV) as shown by its ultra-violet absorption spectrum $\left[\lambda_{\max } 230\right.$ and $284 \mathrm{~m} \mu \quad(\epsilon=6,300$ and 16,400 respectively)]. These two diene-lactones not only confirm the relationship of the $\mathrm{C}-7$ ketone of limonin to the ring $\mathrm{D}$ lactone, but also show the presence of a methyl group at $\mathrm{C}-8$ and of a hydrogen atom at C-9.

The environment of the $\mathrm{C}-7$ ketone group of limonin was defined in a simple manner. Limonin in dry tert.-butanol containing potassium tert.butoxide was rapidly autoxidized to give the diosphenol ( (XXVI): $R=\mathbf{H}$ ) characterized as its acetate ( $(\mathrm{XXVI}): \mathrm{R}=\mathrm{Ac})$. Analogous diosphenols 


\section{SOME ASPECTS OF TERPENOID AND STEROID GHEMISTRY}

( (XXVII) and (XXVIII) respectively) were obtained from deoxylimonin (XIV) and tetrahydrolimonin (XV). These compounds show that limonin contains the system $-\stackrel{\beta}{\mathrm{C}} \mathrm{H}-\stackrel{\alpha}{\mathrm{C}} \mathrm{H}_{2}-\mathrm{CO}-$. The position of the ultra-violet absorption spectrum maximum near $280 \mathrm{~m} \mu$ further indicated that there was very probably only one $\beta-\mathrm{H}$ with respect to the ketone of limonin in the partial formula given above.

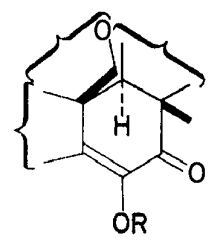

(XXVI)

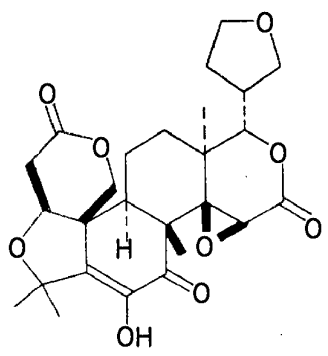

(XXVIII)

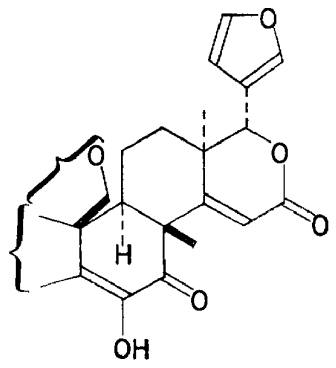

(XXVII)

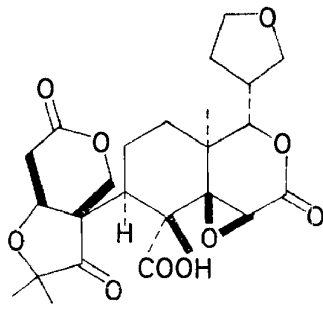

$(X X I X)$

These diosphenol formulations were further confirmed by the ozonolysis of the derivative (XXVIII) from tetrahydrolimonin. This gave in good yield a nor-acid (XXIX), characterized as its methyl ester. Treatment of this acid with aqueous alkali gave formaldehyde. The presence of the grouping $-\mathrm{CO}-\mathrm{O}-\mathrm{CH}_{2}-\underset{\mathrm{C}}{\mathrm{C}}-\mathrm{C}=\mathrm{O}$ in the nor-acid $(\mathrm{XXIX})$ is thus established. In its infra-red absorption spectrum, the methyl ester of (XXVIII) showed a carbonyl band at $1760 \mathrm{~cm}^{-1}$. This cannot be due to either lactones $\mathrm{A}$ or $\mathrm{D}$, for the trisodium salt (two lactones opened and the carboxyl group neutralized) still showed a carbonyl band near $1750 \mathrm{~cm}^{-1}$. It must be ascribed to the new ketone function produced in the ozonolysis. This enhanced frequency is consistent with a cyclopentanone with an $\alpha$-ethereal substituent.

The reaction of carbanions derived from ketones (or equivalent functional groups) with oxygen would appear to be of more significance in degradational and synthetic chemistry than is normally appreciated. Two recent communications are illustrative.

Some steroidal ketones with a progesterone-type side chain react smoothly 
with oxygen in potassium tert.-butoxide solution to furnish 17- $\alpha$-hydroperoxides $^{21}$. For example, the ketone (XXX) gives the hydroperoxide (XXXI) which can be reduced in high yield by zinc dust and acetic acid to the corresponding alcohol (XXXII). The insertion of the 17- $\alpha$-hydroxyl into ketone (XXX), required for the building up of the adrenocortical-type side chain, is not so readily accomplished by more conventional methods.

The carotenoid canthaxanthin (XXXIII) reacts with oxygen under the above specified conditions to give astacene (XXXIV) ${ }^{22}$. This is a reaction which cannot be accomplished by other methods.

Limonilic acid, $\mathrm{C}_{26} \mathrm{H}_{30} \mathrm{O}_{9}{ }^{16}$, was first obtained ${ }^{18}$ by oxidation of limonin in alkaline solution with potassium permanganate, but it is more readily prepared in essentially quantitative yield by treatment of an alkaline solution of limonin with hypoiodite ${ }^{16}$. Limonilic acid is to be formulated as $(\mathrm{XXXV})^{9}$. Its method of formation represents a new procedure for
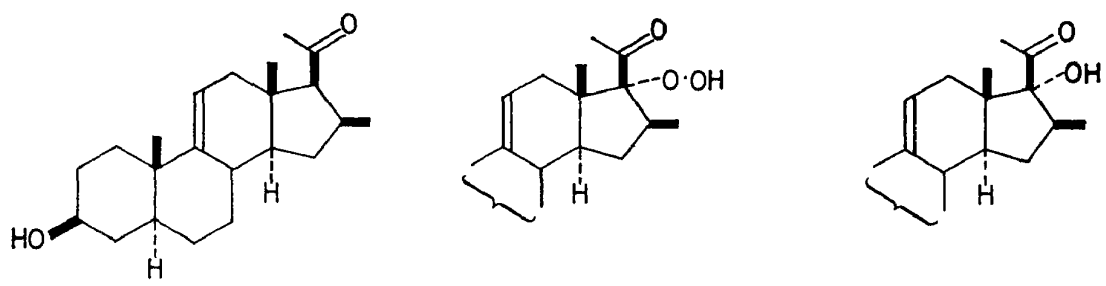

$(\mathrm{XXX})$

$(\mathrm{XXXI})$

(XXXII)<smiles>CC1=C(/C=C/C(C)=C/C=C/C=C(C)/C=C/C=C/C=C(C)/C=C/C=C(C)/C=C/C2=C(C)C(=O)CCC2(C)C)C(C)(C)CCC1=O</smiles><smiles>CC(=O)OCC=CC(C)=CC=CC(C)=CC=CC=C(C)C=CC=C(C)C=CC1=C(C)C(=O)C(O)=CC1(C)C</smiles><smiles>CC(C)(C)C(C)(C)C</smiles>

(XXXV) 


\section{SOME ASPECTS OF TERPENOID AND STEROID GHEMISTRY}

making an ethereal linkage, facilitated, no doubt, by a specially favourable conformational situation.

The work of our group outlined above, coupled with earlier published work on limonin, makes it possible to write without ambiguity the part structure (XXXVI). If we accept a triterpenoid type of biogenesis ${ }^{9}$, and have regard to the formation of acetone in high yield on fusion with potassium hydroxide ${ }^{16}$ and to the formation of naphthalenic products ${ }^{8},{ }^{19}$ on dehydrogenation, then one can write (XXXVII) as a plausible formula for limonin (see Arigoni et al. ${ }^{9}$ ). This was the position in September, 1959, when Professor Robertson was able to state from the X-ray evidence (see Arigoni et al. ${ }^{9}$ ) that limonin was either (VIII) or (XXXVIII). The latter formula is, of course, incompatible with much chemical evidence, and therefore formula (VIII) stands. In addition, the X-ray work provides the complete stereochemistry of the molecule.

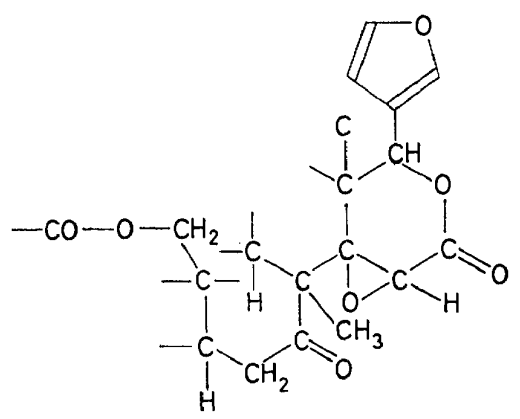

$(\mathrm{XXXVI})$

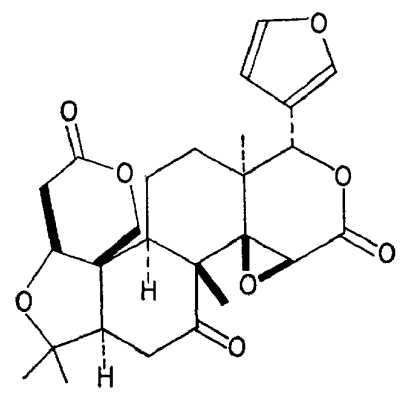

(XXXVIII)

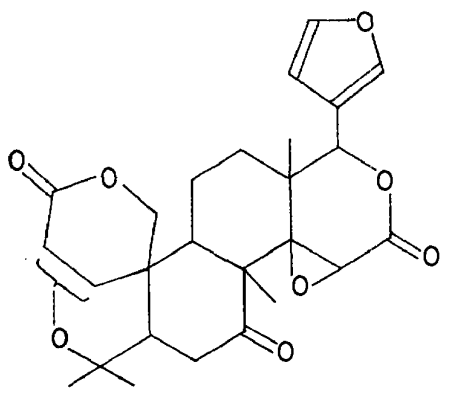

$(X X X V I I)$

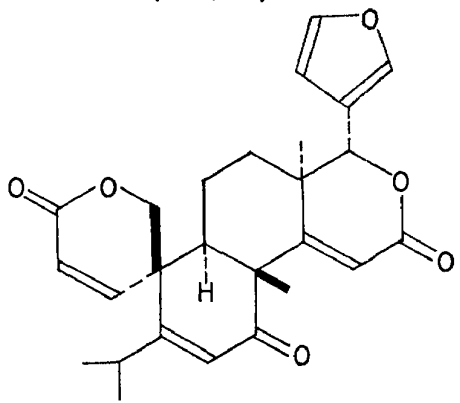

$(X X X I X)$

The formulae (VIII) and (XIV) for limonin and deoxylimonin respectively permit the formulation of citrolin as (XXXIX). The earlier work of Emerson ${ }^{\mathbf{1 6}}$ had established that citrolin contained an $\alpha, \beta$-unsaturated ketone function as well as an $\alpha, \beta$-unsaturated lactone and a furan ring. A study of the hydrogenation of citrolin $^{16}$ appeared to show that these were the only unsaturated groupings present. We noted, however, that the ultraviolet and infra-red absorption spectra of citrolin were in better accord with the presence of two $\alpha, \beta$-unsaturated lactone groups. This was confirmed by the selective hydrogenation of citrolin (under conditions which 
do not attack the unsaturation of ring $\mathrm{D})$ to give a dihydrocitrolin ((XXXIX) ring A saturated). In this compound, the presence of a saturated $\delta$-lactone ring could be seen directly in the infra-red absorption spectrum, and indirectly by differential ultra-violet spectroscopy with respect to deoxylimonin (XIV). The nuclear magnetic resonance spectrum of citrolin confirmed the presence of $4 \mathrm{C}-\mathrm{Me}$ groups.

The two minor bitter principles of citrus species are nomilin, $\mathrm{C}_{28} \mathrm{H}_{34} \mathrm{O}_{9}$, and obacunone, $\mathrm{C}_{26} \mathrm{H}_{30} \mathrm{C}_{7}{ }^{23}$. They have recently been investigated further by Dean and Geissman ${ }^{24}$. Both compounds contain two lactone rings (one of which can be opened reversibly, the other irreversibly), a furan ring, a somewhat unreactive ketone group and an ethereal ring. Nomilin is a $\beta$-acetoxy-lactone which, on treatment with a suitable hot tertiary amine, is converted into the $\alpha, \beta$-unsaturated lactone obacunone with elimination of acetic acid. Upon consideration of these and other published facts discussed in more detail below, and having regard to a probable biogenetic relationship to limonin, we proposed ${ }^{11}$ the formulae (XL) and (XLI) for nomilin and obacunone respectively. The work that we summarize below, whilst not yet providing a complete proof of the correctness of these structures, is, nevertheless, in full accord with them, and confirms many of the functional group relationships. In addition, we have resolved certain anomalies in the earlier work ${ }^{24}$ which were in apparent disagreement with our proposed formulae.

Both nomilin and obacunone, on mild treatment ${ }^{23}$, 24 with alkali, afford obacunoic acid, $\mathrm{C}_{26} \mathrm{H}_{32} \mathrm{O}_{8}$ ( (XLII): $\left.\mathrm{R}=\mathrm{H}\right)$, in which the $\mathrm{A}$ ring lactone has been opened irreversibly as expected of a seven-membered ring.

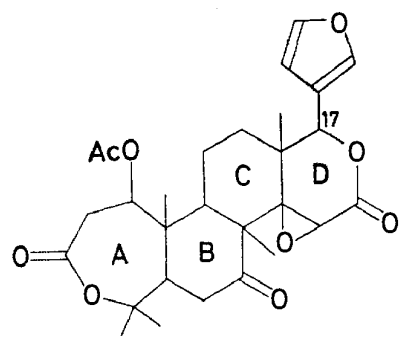

(XL)

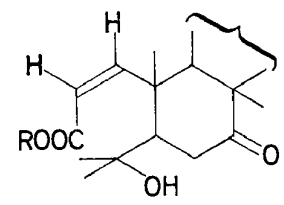

(XLII)

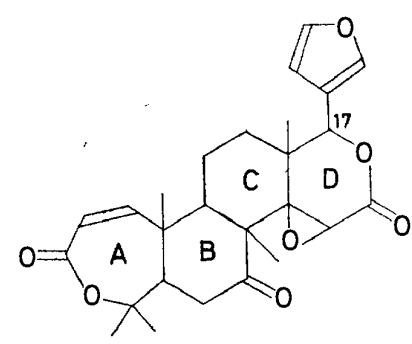

(XLI)

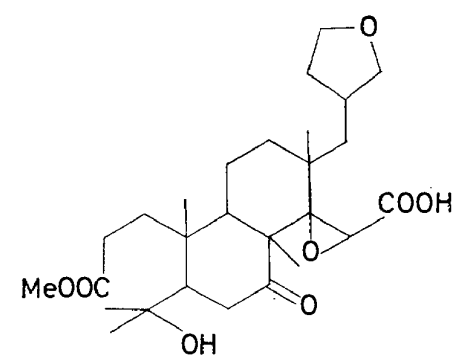

(XLIII) 


\section{SOME ASPEGTS OF TERPENOID AND STEROID GHEMISTRY}

Obacunoic acid has two active hydrogens, in keeping with the presence of a normal alcoholic hydroxyl group, a feature. about which there was some confusion earlier ${ }^{24}$. Methyl obacunoate ${ }^{24}$ ( (XLII): $\mathrm{R}=\mathrm{Me}$ ) likewise showed an $\mathrm{OH}$ band of a normal type in the infra-red absorption spectrum. The nuclear magnetic resonance spectrum of ( $(\mathrm{XLII}): \mathrm{R}=\mathrm{Me}$ ) confirmed the presence of four normal $\mathrm{C}-\mathrm{Me}$ groups $(\tau=8 \cdot 88,8 \cdot 97,9 \cdot 008$ and 9.043$)$, one $\mathrm{C}-\mathrm{Me}(\tau=8 \cdot 618)$ of the type at $\mathrm{C}-13$ in limonin (that is, close to the furan ring), and of a cis- $\beta$-substituted acrylic ester (A-B quartet at $\tau=4.24$ and $4.49(\alpha-\mathrm{H})$ and at $\tau=3.798$ and $4.08(\beta-\mathrm{H}) ; \mathrm{J}_{\mathrm{AB}}=13.4$ $\mathrm{c} / \mathrm{sec}$; see Jackman $\left.{ }^{25}\right)$. In addition, two $\alpha$-hydrogens $(\tau=2 \cdot 506)$ and one $\beta$-hydrogen $(\tau=3.658)$ attached to a furan ring $^{26}$ could be seen easily. One proton with a $\tau$ value of 4.63 indicated $>\mathrm{CH}-\mathrm{O}-$ at $\mathrm{C}-17$, a feature seen in the nuclear magnetic resonance spectra of limonin and its derivatives.

On hydrogenation in acetic acid over palladized charcoal, obacunoic acid consumed 3.74 mols of hydrogen. Methyl obacunoate behaved similarly (3.86 mols uptake), and gave a crystalline methyl ester acid (XLIII) through hydrogenolysis of the D-ring lactone just as in limonin (see above). The consumption of hydrogen in our hands is one mol less than that observed earlier ${ }^{\mathbf{2 4}}$. We conclude, therefore, that obacunone and nomilin are bicarbocyclic like limonin, not monocarbocyclic as proposed ${ }^{24}$ earlier on the basis of the hydrogenation evidence.

Obacunoic acid behaved like limonin on reduction with chromous chloride $^{9}$, and afforded a crystalline deoxyobacunoic acid. This contained an $\alpha, \beta$-unsaturated lactone ring regarded as $\delta$ - because of its frequency in the infra-red absorption spectrum. A similar conclusion as to the size of the reversibly opened (D-ring) lactone can be reached from the infra-red absorption spectra of all obacunoic acid derivatives. Deoxyobacunoic acid behaved like deoxylimonin (see above) in that mild treatment with base gave a product which, on spectroscopic evidence, now lacked the $\alpha, \beta$-unsaturated lactone ring. It could not be crystallized, but was clearly an analogue of deoxylimonic acid (XXI).

Another analogy between limonin and obacunoic acid could be seen in the following transformation. Treatment of the methyl ester acid (XLIII) with dioxan-hydrochloric acid under the conditions needed to transform hexahydrolimoninic acid (XVII) into its rearranged isomer (XVIII) gave an acidic product which, from its infra-red absorption spectrum, was also a $\gamma$-lactone (frequency at $1785 \mathrm{~cm}^{-1}$ ). In addition, this substance showed $\alpha, \beta$-unsaturated ketone absorption in its ultra-violet absorption spectrum, but with a carbonyl frequency in the infra-red absorption spectrum which was abnormally low $\left(1630 \mathrm{~cm}^{-1}\right)$. The same anomalously low carbonyl frequency is found in (XVIII) $\left(1686 \mathrm{~cm}^{-1}\right)$, and must be due to hydrogen bonding with the C-15-hydroxyl. In (XVIII), the $\gamma$-lactone frequency is also rather high at $1789 \mathrm{~cm}^{-1}$. The reaction product is, therefore, formulated as an analogue of (XVIII), although again it could not be crystallized.

On mild treatment with sodium methoxide, methyl obacunoate was converted into a compound conveniently designated iso-obacunoic acid (XLIV). This substance lacked the $\alpha, \beta$-unsaturated acid function of obacunoic acid, and also (see below) the hydroxyl group. The facts are conveniently explain by formula (XLIV) and, indeed, the formation of 


\section{H. R. BARTON}

such an iso-acid is in full accord with the proposed ${ }^{9}$ (see also above) biogenesis of limonin.

Dean and Geissman ${ }^{24}$ made the interesting observation that obacunone gives a positive iodoform test. Under standard conditions ${ }^{27}$, the following yields of iodoform (in parentheses) were obtained: acetophenone (30 per cent), acetonedicarboxylic ester (16, 21 per cent), obacunoic acid (15 per cent), limonin ( 0 per cent), iso-obacunoic acid ( 0 per cent), cinnamic acid ( 0 per cent), crotonic acid ( 0 per cent). These results show that it is the hydroxyisopropyl grouping of obacunoic acid which is responsible for the test. There are two obvious mechanisms which would explain this:

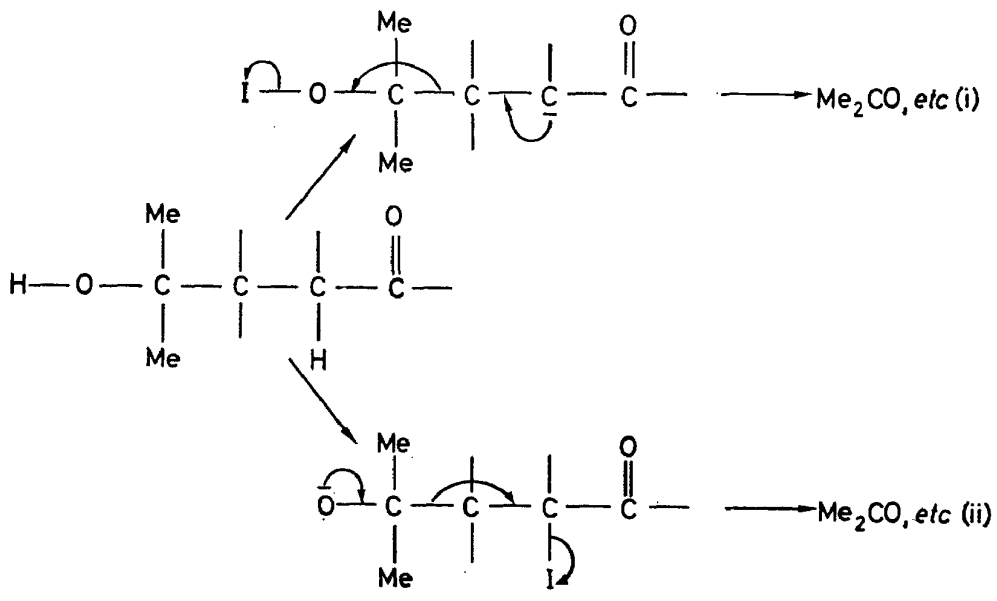

Route (i) would appear more probable, but we do not have any decisive experiment to distinguish between the two. We have shown, however, that suitable model compounds react in the same way. Thus, whilst dihydrocarvone $(\mathrm{XLV})^{28}$ gave no iodoform, its hydrate (XLVI) ${ }^{29}$ gave 4 per cent. Similarly, carvone furnished no iodoform, but its hydrate ( $(\mathrm{XLVII}): \mathrm{X}=\mathrm{O})^{30}$ gave 6 per cent. From the latter reaction, the expected 4,6-diiodo- 0 -cresol ( (XLVIII): $\mathrm{R}=\mathrm{H}$ ), characterized as its 3,5-dinitrobenzoate, could be isolated. $\alpha$-Terpineol ( $(\mathrm{XLVII}): \mathbf{X}=\mathbf{H}_{\mathbf{2}}$ ) gave no iodoform, but dihydroisophotosantonic lactone ((XLIX): $\mathrm{X}=\mathrm{H})^{31}$, where an analogous mechanism as indicated by the arrows in ( $(\mathrm{XLIX}): \mathrm{X}=\mathrm{I}$ ) can operate, gave 4 per cent. These iodoform experiments, taken as a whole, suggest that obacunoic acid has an hydroxyisopropyl group separated by two carbon atoms from the ketone group as already written into formula ( (XLII): $\mathrm{R}=\mathrm{H}$ ).

The environment of the ketone group of obacunoic acid was further defined by autoxidation experiments of the kind already described (see above) for limonin and its derivatives. Alkaline autoxidation of obacunoic acid gave a diosphenol, characterized as its acetate, in the manner expected. However, the $\epsilon$ values for these compounds were significantly lower than for compounds of the limonin series, and both the diosphenol and its acetate analysed for one $\mathrm{H}_{2} \mathrm{O}$ less than expected. In addition, both compounds 


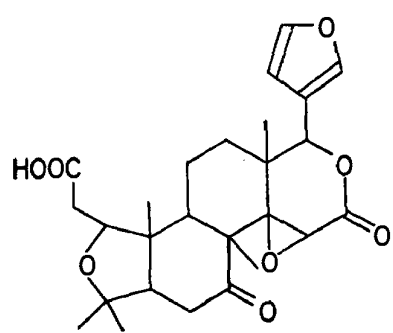

(XLIV)

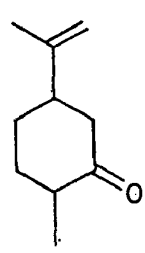

$(\mathrm{XLV})$<smiles>CC1CCC(C(C)(C)O)CC1=O</smiles>

(XLVI)<smiles>[X]C1CC(C(C)(C)O)CCC1C</smiles>

(XLVII)<smiles>[R]Oc1c(C)cc(I)cc1I</smiles>

(XLVIII)<smiles>[X]CC1(C)CCC2C(C)C(=O)OC2C2C3C(C)C(=O)C(=O)C3CC21</smiles>

$(X \operatorname{LIX})$

were neutral, not acidic. Formulae which explain these facts are (L), (LI) and (LIII); according to this scheme, a normal diosphenol acid (L) is first formed, but it then rearranges, if only fleetingly, to (LI), collapse of which (see arrows in (LI) ) gives the diosphenol ( (LIII): $\mathrm{R}=\mathrm{H}$ ).

Autoxidation of iso-obacunoic acid gave an acidic diosphenol with the normal spectroscopic and chemical properties expected of (LII). However, it could not be crystallized.

If all the facts on obacunoic acid are summarized, and the interpretations made in the deduction ${ }^{9}$ of the limonin structure are repeated, then, assuming also that the lactone ring $\mathrm{A}$ of obacunone is 7 -membered, the part expression (LIV) for obacunone can be derived fairly rigidly.

The stereochemistry of obacunone is not defined by the above experiments. However, the change in $[\mathrm{M}]_{\mathrm{D}}$ between limonin and epilimonol is almost exactly the same as that between obacunone and $\alpha$-obacunol, the borohydride reduction product of obacunone ${ }^{24}$, indicating an analogous stereochemical environment. The change in $[\mathrm{M}]_{\mathbf{D}}$ from obacunoic acid to deoxyobacunoic acid is not, however, in good agreement with the corresponding change in the limonin series. We assumed that obacunone was related, stereochemically as well as constitutionally, to limonin and was thus $(\mathrm{LV})$. An attempt to interrelate limonin and obacunone was, therefore, initiated along the following lines.

Limonilic acid (XXXV) was transformed into the corresponding methyl ketone $((\mathbf{L V I}): \mathrm{X}=\mathrm{O})$ by a standard series of reactions ${ }^{32}$, and the latter was then converted into the dithioketal derivative $\left((\mathrm{LVI}): \mathrm{X}=\left(\mathrm{S}-\mathrm{CH}_{2}\right)_{2}\right)$. Preliminary experiments showed that limonilic acid could be reduced back efficiently to limonin by the use of lithium amalgam, and that a typical dithioketal was not reduced by this reagent under the experimental conditions 
D. H. R. BARTON<smiles>CC(C)(O)/C=C1\C(=O)C(O)C2(C)CCCC1C2(C)/C=C\C(=O)O</smiles>

(L)<smiles>CC1(C)OC(CC(=O)O)C2(C)C1=C(O)C(=O)C1(C)CCCC12</smiles>

(LII)

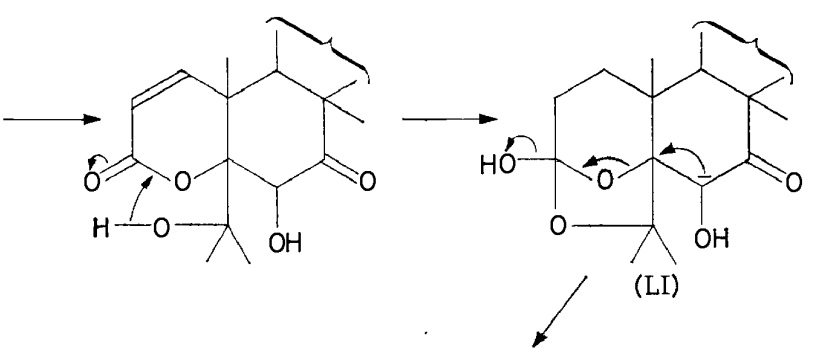

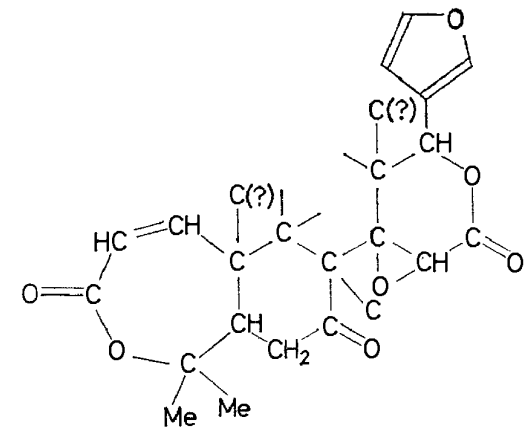

(LIV)

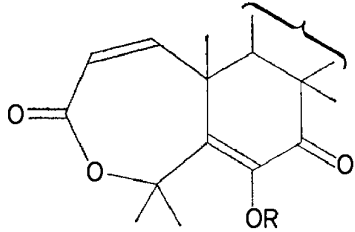

(LIII)

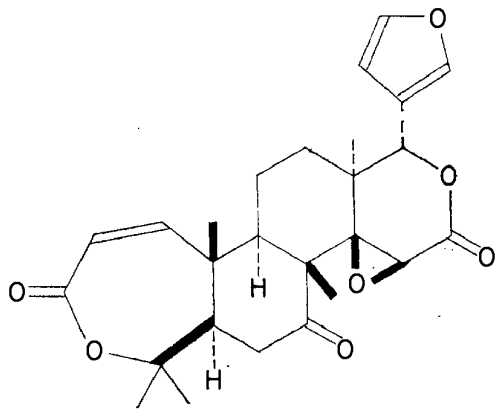

(LV)

employed. Treatment of $\left((\mathrm{LVI}): \mathrm{X}=\left(\mathrm{S}-\mathrm{CH}_{2}\right)_{2}\right)$ in this way, and oxidation of the product with pyridine-chromium trioxide, then furnished the keto-aldehyde (LVII). Conversion of the aldehyde group to methyl should afford a derivative of iso-obacunoic acid. So far, however, it has not been possible to reduce the aldehyde of (LVII) without damaging other functional groups in the molecule.

A preliminary communication by Kubota, Kamikawa, Tokoroyama and Matsuura ${ }^{33}$ has been published in which independent evidence is presented for the part structure (LVIII) for obacunone. All the observations of the Japanese authors are in agreement with our proposed formula (XLI) for this bitter principle.

From consideration of lactonic bitter principles derived from the common triterpenoid-steroid type of biogenesis, we return again to sesquiterpenoid chemistry for an account of some recent work on geigerin carried out in collaboration with Dr Pinhey ${ }^{34}$. Bromination of geigerin (IV) acetate with $\mathcal{N}$-bromosuccinimide gave a derivative whose constitution and stereochemistry were shown by X-ray crystallography ${ }^{35}$ to be as in (LIX). At 


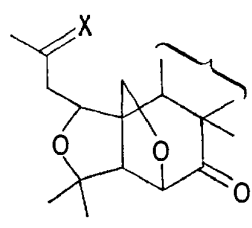

(LVI)

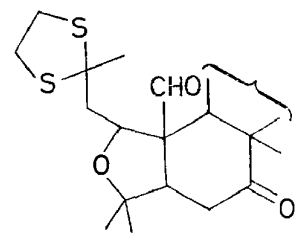

(LVII)<smiles>CC1C(C)(C)C=CC(=O)OC1(C)C</smiles>

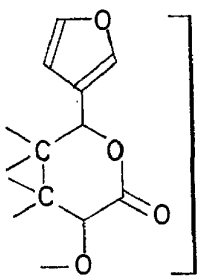

(LVIII)

the same time, a direct correlation between artemisin ( $(\mathrm{LX}): \mathrm{R}=\mathrm{OH})$ and geigerin has confirmed certain aspects of the $\mathrm{X}$-ray investigations ${ }^{35}$, and has proven the absolute stereochemistry of geigerin since that of artemisin was already known ${ }^{36}$.

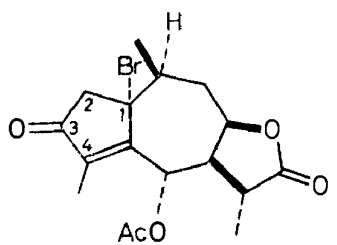

(LIX)

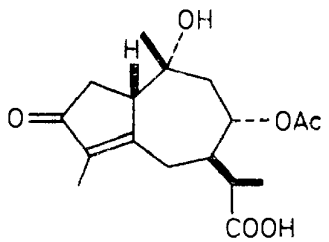

( LXII)

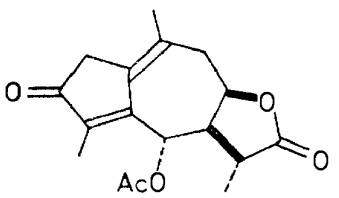

( LXV)<smiles>[R]C1C[C@]2(C)C=CC(=O)C(C)=C2[C@@H]2OC(=O)[C@H](C)[C@H]12</smiles>

(LX)<smiles>CC1=C2CC(=O)CC(C)=C2CC2=C(C)C(=O)C(C)[C@H]2C1</smiles>

(LXIII)

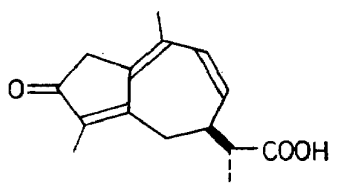

(LXVI)<smiles>[R]C1C[C@H](C)[C@]2(C)CC(=O)C(C)=C2[C@@H]2OC(=O)[C@H](C)[C@@H]12</smiles>

(LXI)

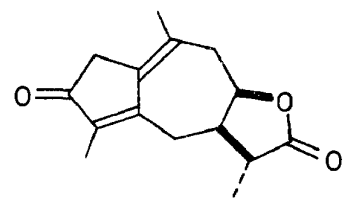

(LXIV)

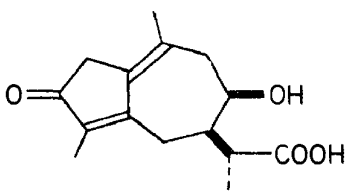

(LXVII) 


\section{H. R. BARTON}

Some years ago, we showed ${ }^{31}$ that santonin $((\mathrm{LX}): \mathrm{R}=\mathrm{H})$ was rearranged by irradiation with ultra-violet light in aqueous acetic acid to give the lactone $((\mathrm{LXI}): \mathrm{R}=\mathrm{H})$. This is a general reaction ${ }^{37,}{ }^{38}$ with obvious applications in the synthesis of naturally occurring perhydroazulene derivatives. Irradiation of artemisin acetate gave a photo-product ${ }^{38}$ ( $(\mathrm{LXI}): \mathrm{R}=\mathrm{OAc}$ ) which, on reduction with chromous chloride, gave the acid (LXII). Treatment of the latter with perchloric acid in acetic acid under controlled conditions furnished the dienone (LXIII). On dissolution in 1 per cent ethanolic potassium hydroxide at room temperature and immediate acidification, the dienone (LXIII) gave an isomeric dienone (LXIV) identical with anhydrogeigerin ${ }^{3}, 34$. The latter can be obtained from geigerin in various ways and, in particular, from the bromo-derivative (LIX) by refluxing with dimethylformamide to give (LXV), followed by reduction of this with chromous chloride. The inversion of configuration on treating (LXIII) with alkali can be easily understood as vinylogous $\beta$-elimination to the trienone (LXVI), followed by immediate $\beta$-directed (from the $\beta$-oriented side-chain) readdition of carboxylate anion with (ultimately) normal hydrolysis of the lactone group to give the hydroxyacid (LXVII). The mildness of the alkaline conditions precludes inversion at position 11 (in the side-chain) which, in any case, is the same ${ }^{36}$ in both artemisin and geigerin ${ }^{35}$. The absolute stereochemistry of geigerin is thus established at all centres except $\mathrm{C}-1$ (see (LIX)). A $\beta$-configuration at this centre has been assigned on the basis of rotatory dispersion studies ${ }^{39}$, so that geigerin can be represented in full detail as in (LXVIII):

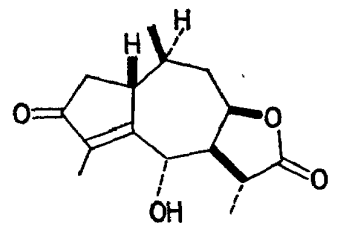

(LXVIII)

It is a pleasure to acknowledge that the work described in the present lecture has been done by my able colleagues Drs F. T. Pinhey, S. K. Pradhan and S. Sternhell and by $\operatorname{Mr}$ F. T. Templeton.

\section{References}

${ }^{1}$ D. H. R. Barton and P. de Mayo. F. Chem. Soc., 1956, 142

2 D. H. R. Barton and C. R. Narayanan. 7. Chem. Soc., 1958, 963

${ }^{3}$ D. H. R. Barton and J. E. D. Levisalles. F. Chem. Soc., 1958, 4518

D. H. R. Barton and P. de Mayo. F. Chem. Soc., 1957, 150

D. H. R. Barton, O. C. Böckman and P. de Mayo. 7. Chem. Soc., 1960, 2263

5 See F. Sorm. This Symposium, p. 533

- See L. Ruzicka. Experientia, 9, 357 (1953)

7 D. H. R. Barton and D. Elad. 7. Chem. Soc., 1956, 2085

${ }^{8}$ A. Melera, K. Schaffner, D. Arigoni and O. Jeger. Helv. Chim. Acta, 40, 1420 (1957)

D. Arigoni, D. H. R. Barton, E. J. Corey and O. Jeger et al. Experientia, 16, 41 (1960)

${ }^{10}$ S. Arnott, A. W. Davie, J. M. Robertson, G. A. Sim and D. G. Watson. Experientia, 16, 49 (1960)

11 D. H. R. Barton, S. K. Pradhan, S. Sternhell and J. T. Templeton. F. Chem. Soc., 1961, 225 


\section{SOME ASPECTS OF TERPENOID AND STEROID CHEMISTRY}

12 D. H. R. Barton, J. F. McGhie, M. K. Pradhan and S. A. Knight. Chem. E Ind. (London), 1954, 1325

D. H. R. Barton, J. F. McGhie, M. K. Pradhan and S. A. Knight. F. Chem. Soc., 1955, 876

D. Arigoni, R. Viterbo, M. Dünnenberger, O. Jeger and L. Ruzicka. Helv. Chim. Acta, 37, 2306 (1954)

${ }^{13}$ W. Lawrie, W. Hamilton, F. S. Spring and H. S. Watson. J. Chem. Soc., 1956, 3272

14 E. R. H. Jones and T. G. Halsall. Fortschr. Chem. org. Naturstoffe, 12, 44 (1955)

${ }^{15}$ C. Djerassi. Optical Rotatory Dispersion, McGraw-Hill, New York (1960)

${ }^{16}$ O. H. Emerson. J. Am. Chem. Soc., 74, 688 (1952)

${ }^{17}$ B. V. Chandler and J. F. Kefford. Australian F. Sci., 14, 24 (1951)

${ }^{18}$ T. A. Geissman and V. Tulagin. 7. Org. Chem., 11, 760 (1946)

${ }^{18}$ G. Koller and H. Czerny. Monatsh. Chem., 67, 248 (1936)

${ }^{20}$ See D. H. R. Barton, E. Miller and H. T. Young. F. Chem. Soc., 1951, 2598

${ }^{21}$ E. J. Bailey, J. Elks and D. H. R. Barton. Proc. Chem. Soc., 1960, 214

${ }^{22}$ J. B. Davis and B. G. L. Weedon. Proc. Chem. Soc., 1960, 182

23 O. H. Emerson. F. Am. Chem. Soc., 70, 545 (1948); 73, 2621 (1951)

${ }^{24}$ F. M. Dean and T. A. Geissman. 7. Org. Chem., 23, 596 (1958)

${ }^{25}$ L. M. Jackman. Applications of Nuclear Magnetic Resonance Spectroscopy in Organic Chemistry, Pergamon Press, London (1959)

${ }^{26}$ E. J. Corey, G. Slomp, S. Dev, S. Tobinaga and E. R. Glazier. J. Am. Chem. Soc., 80, 1204 (1958)

27 L. F. Fieser. Experiments in Organic Chemistry, Heath, Boston (1955)

${ }^{28} \mathrm{O}$. Wallach and H. Schrader. Ann., 279, 377 (1894)

${ }^{29} \mathrm{H}$. Rupe and K. Liechtenhan. Ber. deut. chem. Ges., 39, 1124 (1906)

${ }^{30}$ E. Knoevenagel and O. Samel. Ber. deut. chem. Ges., 39, 677 (1906)

${ }^{31}$ D. H. R. Barton, P. de Mayo and M. Shafiq. 7. Chem. Soc., 1957, 929

32 e.g. M. L. Wolfrom and R. L. Brown. 7. Am. Chem. Soc., 65, 1516 (1943)

${ }^{3 s}$ T. Kubota, T. Kamikawa, T. Tokoroyama and T. Matsuura. Tetrahedron Letters, No. 8, 1 (1960)

34 D. H. R. Barton and J. T. Pinhey. Proc. Chem. Soc., 1960, 279

${ }^{36} \mathrm{~J}$. A. Hamilton, A. T. McPhail and G. A. Sim. Proc. Chem. Soc., 1960, 278

${ }^{86}$ See W. Cocker and T. B. H. McMurry. Tetrahedron, 8, 181 (1960)

${ }^{37}$ D. H. R. Barton and W. C. Taylor. 7. Chem. Soc., 1958, 2500.

D. H. R. Barton, J. E. D. Levisalles and J. T. Pinhey. Unpublished data

K. Weinberg, E. C. Utzinger, D. Arigoni and O. Jeger. Helv. Chim. Acta, 43, 236 (1960)

${ }^{38}$ D. H. R. Barton. Proc. Chem. Soc., 1958, 61

D. H. R. Barton. Helv. Chim. Acta, 42, 2604 (1959)

${ }^{39}$ C. Djerassi, J. Osiecki and W. Herz. 7. Org. Chem., 22, 1361 (1957) 